\title{
Role of intravenous iron in the treatment of anemia in patients with gastrointestinal tract tumors undergoing chemotherapy: a single-center, observational study
}

This article was published in the following Dove Press journal:

International Journal of General Medicine

Joana Lima

Patrícia Gago

Mariana Rocha

Inês Grilo

Rosa Gomes

Michael Luís

Teresa Sarmento

Antonio Teira

Marta Sousa

Miguel Barbosa

Medical Oncology Department, Centro Hospitalar de Trás-os-Montes e Alto Douro, EPE, Vila Real, Portugal

Correspondence: Joana Lima Medical Oncology Department, Centro Hospitalar de Trás-os-Montes e Alto Douro, EPE, Avenida da Noruega, 5000508 , Vila Real, Portugal

$\mathrm{Tel}+351915383554$

Fax +35I 259300503

Email med.joana.lima@gmail.com
Purpose: The prevalence of anemia ranges between $30 \%$ and $90 \%$ in cancer patients, affecting the health status, quality of life, and treatment outcome. Therefore, a proper diagnosis and management of anemia is crucial in these patients. Iron deficiency is diagnosed in $\sim 32 \%-60 \%$ of the cases. In this observational study, we evaluated the efficacy and safety of intravenous iron (ferric carboxymaltose [FCM], Ferinject ${ }^{\circledR}$ ) in the treatment of iron-deficiency anemia in patients with gastrointestinal tumors undergoing palliative or adjuvant chemotherapy.

Patients and methods: Thirty patients with gastrointestinal tumors undergoing chemotherapy diagnosed with iron-deficiency anemia were included in the study and received at least one FCM administration. The need for iron replacement therapy was evaluated by the assessment of hemoglobin and iron status parameters, and patients could be treated with FCM during 12-14 weeks. Paired $t$-test approach was used to evaluate the mean differences between the baseline and the end of the study. A $p$-value of $<0.05$ was considered statistically significant.

Results: Data showed that there was a statistically significant increase in the mean of hemoglobin (10.3 vs $11.2 \mathrm{~g} / \mathrm{dL})$, ferritin (230.3 vs $877.0 \mathrm{ng} / \mathrm{mL})$, transferrin saturation $(13.0 \% \mathrm{vs}$ $19.7 \%$ ), and serum iron ( $42.3 \mathrm{vs} 59.6 \mathrm{mg} / \mathrm{mL}$ ) from the baseline to the end of the study in cancer patients. Most of the patients $(n=25)$ were only administered one dose of FCM. There was one FCM-related adverse event during the study.

Conclusion: FCM was well tolerated and had a positive impact in the treatment of irondeficiency anemia in patients with gastrointestinal tract tumors undergoing chemotherapy.

Keywords: anemia, ferric carboxymaltose, gastrointestinal tract tumors, oncology

\section{Introduction}

Anemia is a common comorbid condition observed in cancer patients. ${ }^{1}$ Its prevalence ranges between $30 \%$ and $90 \%$, according to the type of cancer, definition of anemia, disease stage, and type of treatment. ${ }^{1}$ Chemotherapy is one of the most important causes of anemia in cancer patients. ${ }^{2}$ In fact, some chemotherapeutic agents induce myelosuppression, and their effect may accumulate over the course of chemotherapy, resulting in a steady increase of the incidence of anemia in every new cycle of chemotherapy. ${ }^{2}$ Moreover, $32 \%-60 \%$ of the cancer patients can present iron deficiency, resulting in anemia in the majority of them. ${ }^{3}$ Particularly in patients with gastrointestinal tumors, the prevalence of anemia is $\sim 50 \%$ and, in most of the cases, it is caused by iron deficiency. ${ }^{4}$ 
Anemia affects the health status and quality of life of cancer patients and has a negative impact on treatment outcome, prognosis, and survival. ${ }^{2,5}$ Thus, it is important to correctly diagnose and manage anemia in cancer patients. Currently, these patients are treated with blood transfusions, erythropoiesis-stimulating agents (ESAs), or iron replacement therapy. ${ }^{5}$

Transfusion of red blood cells is indicated in patients requiring a quick correction of anemia, as it rapidly increases hemoglobin $(\mathrm{Hb})$ and hematocrit levels. However, transfusions are expensive and are associated with risks, such as transfusion-related reactions, congestive heart failure, bacterial contamination, viral infections, and iron overload. ${ }^{2,4}$ ESAs (epoetin and darbepoetin) reduce the need for transfusion of red blood cells but increase the risk of thromboembolic events and death. Moreover, some studies showed that ESAs may be associated with tumor progression, though further research is required to enlighten this potential effect. ${ }^{6}$

Iron replacement therapy is indicated for the treatment of iron-deficiency anemia, which may be classified as absolute (depletion of iron reserves and low ferritin levels), or functional (normal or increased iron reserves and ferritin levels). ${ }^{5}$ The current orientations of the Portuguese Directorate-General of Health (DGS) recommend the evaluation of complete blood count and iron status parameters in anemic patients and, if applicable, the correction of iron deficiency prior to the treatment with an ESA. ${ }^{7}$

Intravenous iron administration is more effective than oral iron administration, as it overcomes the problems of malabsorption that are frequent in cancer patients. In addition, oral iron is poorly tolerated by many patients due to its adverse events, which include abdominal pain, diarrhea, and constipation. ${ }^{8}$ Ferric carboxymaltose (FCM) is an intravenous iron formulation (iron(III)-hydroxide polymaltose complex), which was developed to overcome the limitations of other intravenous iron formulations. ${ }^{9}$ Iron complexes consisting of carbohydrates (eg, sucrose, dextran, and dextrin) have been used due to their similarity to ferritin. ${ }^{10}$ These complexes do not release ionic iron at neutral $\mathrm{pH}$, but the iron is therapeutically available, as the complexes are metabolized and the iron can either be delivered to the transport system or be stored in ferritin. ${ }^{10}$

FCM has already been studied in cancer patients. ${ }^{5}$ Recent evidence suggests that these formulations are effective and safe in the correction and prevention of anemia in cancer patients. ${ }^{89}$ Moreover, the efficacy of FCM in patients with gastrointestinal tumors diagnosed with iron-deficiency anemia has already been reported, as it increases $\mathrm{Hb}$ and serum ferritin concentrations. ${ }^{11-13}$

Although there are some concerns associated with intravenous iron administration, such as allergic reaction, iron accumulation in tissues, and scarce information about its efficacy and safety in the treatment of anemia in cancer patients, administration of intravenous iron is recommended by several guidelines. ${ }^{711,14} \mathrm{FCM}$ is currently marketed in Europe as Ferinject ${ }^{\circledR} 50 \mathrm{mg}$ iron/mL solution for injection/ infusion and is indicated for the treatment of iron deficiency when oral iron preparations are ineffective or cannot be used. FCM has several advantages when compared with other iron formulations, such as better and more rapid hematologic response and better tolerability. ${ }^{15}$ Moreover, FCM can be administered once a week, whereas iron sucrose is administered twice or thrice a week, implying additional perfusion sessions, which may compromise the therapeutic compliance of cancer patients. ${ }^{15}$ In addition, FCM allows a better hematologic response and reduces the need of red blood cell transfusion in cancer patients, either in monotherapy or in combination with ESAs, and is also a cost-effective alternative for the treatment of anemia in these patients. ${ }^{10,14,16,17}$

This observational study aimed to evaluate the efficacy and safety of intravenous iron (FCM) in the treatment of irondeficiency anemia in patients with gastrointestinal tumors undergoing palliative or adjuvant chemotherapy.

\section{Patients and methods}

This was an observational study performed at a single center (Centro Hospitalar de Trás-os-Montes e Alto Douro, E.P.E, Vila Real, Portugal). The protocol was approved by the local Ethics Committee for Health (Comissão de Ética para a Saúde), and the study was conducted in accordance with the International Conference of Harmonization Good Clinical Practice and all applicable laws and regulations. All patients gave free written informed consent prior to the participation in the study. All study procedures were performed per routine clinical practice.

The study included 30 adults $(\mathrm{n}=30), 18$ men and 12 women with gastrointestinal tumors undergoing palliative or adjuvant chemotherapy diagnosed with iron-deficiency anemia. Inclusion criteria were $\mathrm{Hb} \leq 11 \mathrm{~g} / \mathrm{dL}$ or a reduction $\geq 2 \mathrm{~g} / \mathrm{dL}$ since the start of the current chemotherapy regimen, and ferritin $<30 \mathrm{ng} / \mathrm{mL}$ and transferrin saturation (TSAT) $<20 \%$ or ferritin $30-800 \mathrm{ng} / \mathrm{mL}$, and TSAT $<50 \%$. Patients who needed to receive red blood cell transfusion, were being treated with ESAs, and received any oral iron formulation within 1 week before the screening or any intravenous iron 
formulation within the previous 4 weeks before the screening were excluded. Other key exclusion criteria included any evidence of iron overload or disorders of iron metabolism, moderate to severe hepatic or renal impairment, and acute or chronic infection, asthma, eczema, or atopic allergies.

Patients underwent chemotherapy treatment every week, every 2 weeks, or every 3 weeks, according to their chemotherapy regimen. During the study period (12-14 weeks), in every visit, the need of continuation of iron replacement therapy was evaluated and, if necessary, patients were treated with FCM, according to the approved summary of product characteristics, until anemia or iron deficiency was corrected. $^{18}$

Complete blood count, iron status parameters (serum iron, ferritin, transferrin, iron-binding capacity, TSAT, and safety laboratory tests), body weight, and physical examination were performed and recorded at every study visit.

The primary study endpoint was to evaluate the mean absolute change from baseline in $\mathrm{Hb}$ levels. The secondary study endpoints were the evaluation of mean absolute change in iron status parameters and the assessment of FCM-related adverse events.

The paired $t$-test approach was used to evaluate the mean differences between the baseline and the end of the study. The mean differences from baseline and the corresponding $95 \%$ CIs were graphically represented for week 0 , week 2 ( \pm 3 days), week 4 ( \pm 1 week), week 8 ( \pm 1 week), and week 12 ( \pm 2 weeks). A $p$-value of $<0.05$ was considered statistically significant. Adverse events were coded using MedDRA 20.1.

\section{Results}

A total of 38 adult cancer patients were screened for participation. Five patients were not enrolled in the study because $\mathrm{Hb}$ levels were $>11 \mathrm{~g} / \mathrm{dL}$ or did not have a reduction $\geq 2 \mathrm{~g} /$ $\mathrm{dL}$ from the start of the current chemotherapy regimen and two patients needed a red blood cell transfusion. One patient who fulfilled with all the selection criteria died before the first FCM administration. Thirty patients were administered at least one dose of FCM and constituted the efficacy population. Fifteen patients completed the study with no major protocol violations. Fifteen patients were discontinued, due to lost to follow-up $(n=8)$, treatment with blood transfusion or $\operatorname{ESA}(n=5)$, suspension of chemotherapy treatment $(n=1)$, and study visit occurring out of the subject's study period $(n=1)$. Table 1 summarizes the demographic and baseline characteristics of efficacy population. In this population, the median age was 67 years (60-76 years) and 60\% were male. Most of the patients underwent chemotherapy session every 2 weeks $(65.5 \%)$ and had colorectal cancer (76.7\%). Throughout the study, there were 35 administrations of FCM, with a dose of $1000 \mathrm{mg}$. Most of subjects $(n=25)$ were administered only $1000 \mathrm{mg}$ of FCM. Five patients received two administrations (1000 mg each) of FCM.

In the efficacy population, the mean (SD) Hb concentration was $10.3(0.6) \mathrm{g} / \mathrm{dL}$ at baseline and $11.2(1.6) \mathrm{g} / \mathrm{dL}$ at

Table I Summary of demographic baseline characteristics of the efficacy population

\begin{tabular}{|c|c|c|c|c|c|c|}
\hline Variable & Total & & Female & & Male & \\
\hline $\mathrm{N}(\%)$ & 30 & $(100.0)$ & 12 & $(40.0)$ & 18 & $(60.0)$ \\
\hline \multicolumn{7}{|l|}{ Age (years) } \\
\hline n (\%) & 30 & $(100.0)$ & 12 & $(40.0)$ & 18 & $(60.0)$ \\
\hline Median (IQR) & 67.0 & $(60.0,75.8)$ & 68.5 & $(61.5,73.5)$ & 65.0 & $(58.5,78.0)$ \\
\hline \multicolumn{7}{|l|}{ Height $(\mathrm{cm})$} \\
\hline n (\%) & 29 & $(96.7)$ & 12 & $(4 I .4)$ & 17 & $(58.6)$ \\
\hline Median (IQR) & 163.0 & $(158.0,169.0)$ & 157.0 & $(154.2,161.2)$ & 168.0 & $(164.0,179.0)$ \\
\hline \multicolumn{7}{|l|}{ Weight (kg) } \\
\hline n (\%) & 29 & $(96.7)$ & 11 & $(37.9)$ & 18 & $(62.1)$ \\
\hline Median (IQR) & 66.0 & $(56.0,79.0)$ & 62.1 & $(52.2,70.5)$ & 67.0 & $(57.2,79.8)$ \\
\hline \multicolumn{7}{|c|}{ Chemotherapy regimen, $n(\%)$} \\
\hline Every 2 weeks & 19 & $(65.5)$ & 9 & $(81.8)$ & 10 & $(55.6)$ \\
\hline Every 3 weeks & 5 & $(17.2)$ & 2 & $(18.2)$ & 3 & $(16.7)$ \\
\hline Every week & 5 & $(17.2)$ & 0 & $(0.0)$ & 5 & $(27.8)$ \\
\hline \multicolumn{7}{|c|}{ Gastrointestinal neoplasia, n (\%) } \\
\hline High & 7 & $(23.3)$ & 2 & $(16.7)$ & 5 & $(27.8)$ \\
\hline Low & 23 & $(76.7)$ & 10 & (83.3) & 13 & $(72.2)$ \\
\hline
\end{tabular}

Abbreviation: IQR, interquartile range. 
Table 2 Hemoglobin, other hemogram parameters and iron status parameters at baseline, at the end of the study and the corresponding absolute change

\begin{tabular}{|c|c|c|c|c|c|c|c|}
\hline \multirow{2}{*}{$\begin{array}{l}\text { Variable } \\
\text { Hemoglobin }(\mathrm{g} / \mathrm{C}\end{array}$} & \multicolumn{2}{|c|}{ Baseline } & \multicolumn{2}{|c|}{ End of study } & \multicolumn{2}{|c|}{ Absolute change } & \multirow[t]{2}{*}{$p$-value } \\
\hline & & & & & & & \\
\hline Mean (SD) & 10.3 & $(0.6)$ & 11.2 & $(1.6)$ & 0.9 & $(1.3)$ & 0.001 \\
\hline \multicolumn{8}{|c|}{ Serum iron $(\mathrm{mg} / \mathrm{mL})$} \\
\hline Mean (SD) & 42.3 & (13.9) & 59.6 & $(26.9)$ & 17.4 & $(26.6)$ & 0.001 \\
\hline \multicolumn{8}{|c|}{ Ferritin $(\mathrm{ng} / \mathrm{mL})$} \\
\hline Mean (SD) & 230.3 & $(248.1)$ & 877.0 & $(601.2)$ & 646.7 & $(455.7)$ & $<0.00$ I \\
\hline \multicolumn{8}{|c|}{ Transferrin (mg/mL) } \\
\hline Mean (SD) & 244.3 & $(66.0)$ & 205.7 & $(61.8)$ & -38.5 & $(39.2)$ & $<0.001$ \\
\hline \multicolumn{8}{|c|}{ Iron binding capacity $(\mu \mathrm{g} / \mathrm{dL})$} \\
\hline Mean (SD) & 339.7 & $(75.6)$ & 301.1 & $(89.2)$ & -38.6 & $(62.8)$ & 0.002 \\
\hline \multicolumn{8}{|l|}{ TSAT (\%) } \\
\hline Mean (SD) & 13.0 & $(4.3)$ & 19.7 & (6.7) & 6.7 & $(6.9)$ & $<0.001$ \\
\hline \multicolumn{8}{|l|}{$\mathrm{MCV}(\mathrm{fL})$} \\
\hline Mean (SD) & 87.0 & (7.7) & 92.5 & (8.9) & 5.4 & $(5.4)$ & $<0.00$ I \\
\hline \multicolumn{8}{|l|}{$\mathrm{MCH}(\mathrm{pg})$} \\
\hline Mean (SD) & 28.4 & (3.0) & 30.5 & (3.3) & 2.1 & $(2.3)$ & $<0.001$ \\
\hline \multicolumn{8}{|l|}{$\mathrm{MCHC}(\mathrm{g} / \mathrm{dL})$} \\
\hline Mean (SD) & 32.5 & $(1.2)$ & 33.0 & $(1.1)$ & 0.5 & $(1.3)$ & 0.059 \\
\hline \multicolumn{8}{|l|}{ RDW (\%) } \\
\hline Mean (SD) & 16.8 & (3.0) & 17.0 & (3.3) & 0.2 & (3.7) & 0.800 \\
\hline
\end{tabular}

Abbreviations: MCV, mean corpuscular volume; $\mathrm{MCH}$, mean corpuscular hemoglobin; $\mathrm{MCHC}$, mean corpuscular hemoglobin concentration; RDW, red cell distribution width; TSAT, transferrin saturation.

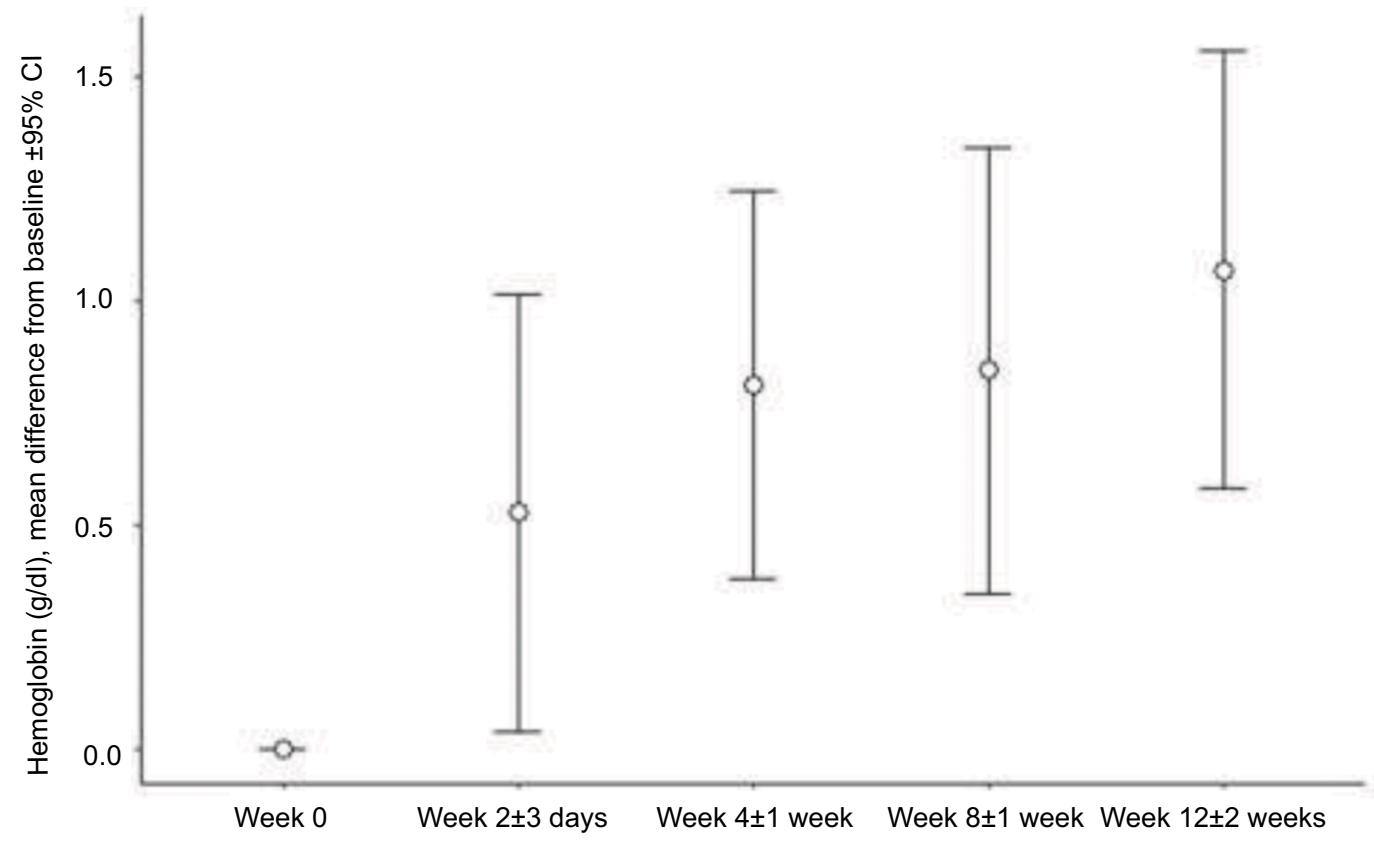

$\begin{array}{lccccc}\text { Number of evaluations } & 30 & 19 & 27 & 18 & 19 \\ \text { (number of subjects in the study) } & (30) & (30) & (29) & (21) & (15)\end{array}$

Figure I Evaluation of the difference from baseline of hemoglobin concentrations throughout the study. 
the end of the study (Table 2). Figure 1 shows the difference from baseline at weeks $0,2,4,8$, and 12 in the patients who had valid measurements at these study times. A gradual increase in $\mathrm{Hb}$ concentrations in patients treated with FCM was observed throughout the study. From week 10 to week 14 , there were 19 observed evaluations of $\mathrm{Hb}$; however, four of these patients were discontinued before week 12 . The median and interquartile range times of patients' follow-up were 11.4 (6.8-12.1) weeks.

The mean (SD) baseline serum iron was 42.3 (13.9) $\mathrm{mg} /$ $\mathrm{mL}$, ferritin was $230.3(248.1) \mathrm{ng} / \mathrm{mL}$, and TSAT was $13.0 \%$ (4.3\%). At the end of the study, serum iron was 59.6 (26.9) $\mathrm{mg} / \mathrm{mL}$, ferritin was 877.0 (601.2) $\mathrm{ng} / \mathrm{mL}$, and TSAT was $19.7 \%(6.7 \%)$ (Table 2). All these increases were statistically significant. There was also a significant increment on transferrin, iron binding capacity, mean corpuscular volume, mean corpuscular $\mathrm{Hb}$, and mean corpuscular $\mathrm{Hb}$ concentration after FCM administration.

Regarding safety results, there was one FCM-related adverse event ("skin and subcutaneous tissue disorders") reported by one patient during the study period.

\section{Discussion}

Anemia is commonly observed in cancer patients, and it impacts their healthy status, quality of life, and cancer treatment. ${ }^{2,4}$ This condition is usually treated with blood transfusions, ESAs, or iron replacement therapy. ${ }^{5}$ The efficacy of intravenous iron in the treatment of iron-deficiency anemia in cancer patients, particularly in those diagnosed with gastrointestinal tumors, is still poorly known.

This observational study aimed to evaluate the efficacy in the treatment of iron-deficiency anemia in patients with gastrointestinal tumors undergoing palliative or adjuvant chemotherapy. The study results showed that patients with gastrointestinal tumors undergoing palliative or adjuvant chemotherapy diagnosed with iron-deficiency anemia showed a progressive increase of $\mathrm{Hb}$ levels and an increment in iron status parameters after treatment with FCM. Moreover, most of the subjects registered these increases after only one administration of FCM.

Other published studies corroborate that FCM improves $\mathrm{Hb}$ and iron status parameters in cancer patients. A retrospective study in gastrointestinal cancer patients diagnosed with iron-deficiency anemia showed a significant increase in $\mathrm{Hb}$ levels after treatment with FCM. This study also revealed that low ferritin baseline levels seem to be a good predictor of therapy response. ${ }^{12}$ Other study reported that cancer patients with baseline $\mathrm{Hb}$ levels up to $11.0 \mathrm{~g} / \mathrm{dL}$ and serum ferritin up to $500 \mathrm{ng} / \mathrm{mL}$ benefited from FCM, which is in agreement with the baseline values observed in our study. ${ }^{11}$ Moreover, the administration of intravenous iron to anemic cancer patients can significantly increase $\mathrm{Hb}$ concentrations, which may increase their quality of life and performance status and reduce the need for ESAs and/or blood transfusions. ${ }^{13,19-21}$

Notwithstanding, our results also showed that half of the patients $(n=15)$ did not complete the study, and five of them had to be treated with ESAs or blood transfusion. Thus, the administration of intravenous iron may not be effective for all the cases of iron-deficiency anemia in cancer patients. One explanation for this fact is that after the first administration of FCM, ferritin levels increased to levels $>800 \mathrm{ng} / \mathrm{mL}$; hence, no further administrations were allowed per protocol. However, some of these patients still had anemia and/ or iron deficiency $(\mathrm{Hb}<11 \mathrm{~g} / \mathrm{dL}$ and/or TSAT $<20 \%)$, and needed to be treated with ESAs or blood transfusion, being discontinued from the study. This may explain why most of the patients were administered only one dose of FCM and why iron deficiency is not corrected at the end of the study (TSAT $=19.7 \%$ ). Nevertheless, a recent study showed a positive response in $\mathrm{Hb}$ levels in patients with ferritin >800 ng/ $\mathrm{mL}$ or TSAT $\geq 50 \%$, after the administration of intravenous iron. ${ }^{22}$ Thus, this treatment may also be effective in cancer patients with anemia who have high levels of ferritin.

This study has some limitations, such as the lack of a control group for analyzing the results. Also, the number of study patients is low; hence, further studies with a larger sample size are required to confirm these results.

\section{Conclusion}

In conclusion, FCM was generally well tolerated and had a positive impact in the treatment of iron-deficiency anemia in patients with gastrointestinal tract tumors undergoing chemotherapy. Therefore, this treatment may be effective for this type of anemia in some patients, avoiding or delaying the treatment with ESAs and/or blood transfusions.

\section{Disclosure}

The authors report no conflicts of interest in this work.

\section{References}

1. Knight K, Wade S, Balducci L. Prevalence and outcomes of anemia in cancer: A systematic review of the literature. Am J Med. 2004;116:11-26.

2. Dicato M, Plawny L, Diederich M. Anemia in cancer. Ann Oncol. 2010;21(Suppl 7):vii167-vii172.

3. National Compreensive Cancer Network. Cancer- and ChemotherapyInduced Anemia. Version 2. 2017 - November 16, 2016. https:// www.nccn.org/professionals/physician_gls/pdf/anemia.pdf. Accessed January 3, 2018. 
4. Ludwig Prof. H, Müldür E, Endler G, Hübl W. Prevalence of iron deficiency across different tumors and its association with poor performance status, disease status and anemia. Ann Oncol. 2013;24(7):1886-1892.

5. Gilreath JA, Stenehjem DD, Rodgers GM. Diagnosis and treatment of cancer-related anemia. Am J Hematol. 2014;89(2):203-212.

6. Tonia T, Mettler A, Robert N, et al. Erythropoietin or darbepoetin for patients with cancer. Cochrane Database Syst Rev. 2012;12(12): CD003407.

7. Norma da Direção-Geral da Saúde. Abordagem, Diagnóstico e Tratamento da Ferropénia no Adulto [Portuguese Directorate-General of Health norm on approach, diagnosis and treatment of iron deficiency in adults]; number 030/2013; revised April 9, 2015. Available from: https://www.dgs.pt/?cr=25229. Accessed January 3, 2018. Portuguese.

8. Santiago P. Ferrous versus ferric oral iron formulations for the treatment of iron deficiency: a clinical overview. ScientificWorldJournal. 2012;2012:846824.

9. Geisser P, Banké-Bochita J. Pharmacokinetics, safety and tolerability of intravenous ferric carboxymaltose: a dose-escalation study in volunteers with mild iron-deficiency anaemia. Arzneimittelforschung. 2011;60(6):362-372.

10. Funk F, Ryle P, Canclini C, Neiser S, Geisser P. The new generation of intravenous iron: chemistry, pharmacology, and toxicology of ferric carboxymaltose. Arzneimittelforschung. 2010;60(6a):345-353.

11. Steinmetz T, Tschechne B, Harlin O, et al. Clinical experience with ferric carboxymaltose in the treatment of cancer- and chemotherapyassociated anaemia. Ann Oncol. 2013;24(2):475-482.

12. Verhaeghe L, Bruyneel L, Stragier E, Ferrante M, Dierickx D, Prenen H. The effectiveness of intravenous iron for iron deficiency anemia in gastrointestinal cancer patients: a retrospective study. Ann Gastroenterol. 2017;30(6):654-663.
13. Lebrun F, Klastersky J, Levacq D, Wissam Y, Paesmans M. Intravenous iron therapy for anemic cancer patients: a review of recently published clinical studies. Support Care Cancer. 2017;25(7):2313-2319.

14. Gemici C, Yetmen O, Yaprak G, et al. Is there any role of intravenous iron for the treatment of anemia in cancer? BMC Cancer. 2016;16:661.

15. Keating GM. Ferric carboxymaltose: a review of its use in iron deficiency. Drugs. 2015;75(1):101-127.

16. Calvet X, Ruíz MÀ, Dosal A, et al. Cost-minimization analysis favours intravenous ferric carboxymaltose over ferric sucrose for the ambulatory treatment of severe iron deficiency. PLoS One. 2012;7(9).

17. Toledano A, Luporsi E, Morere JF, et al. Clinical use of ferric carboxymaltose in patients with solid tumours or haematological malignancies in France. Support Care Cancer. 2016;24(1):67-75.

18. Ferinject (ferric carboxymaltose) [summary of prescribing information]. Vifor Pharma UK Limited. Available from: https:/www.medicines. org.uk/emc/medicine/24167/SPC/Ferinject+(ferric+carboxymaltose) /. Accessed July 5, 2018.

19. Calleja JL, Delgado S, del Val A, et al. Ferric carboxymaltose reduces transfusions and hospital stay in patients with colon cancer and anemia. Int J Colorectal Dis. 2016;31(3):543-551.

20. Cella D. The longitudinal relationship of hemoglobin, fatigue and quality of life in anemic cancer patients: results from five randomized clinical trials. Ann Oncol. 2004;15(6):979-986.

21. Keeler BD, Simpson JA, Ng S, et al. The feasibility and clinical efficacy of intravenous iron administration for preoperative anaemia in patients with colorectal cancer. Color Dis. 2014;16(10):794-800.

22. Park S, Jung CW, Jang JH. Intravenous Iron Supplementation Alone for Treatment of Anemia in Cancer Patients. Blood. 2017; 130(Suppl 1):4756.
International Journal of General Medicine

\section{Publish your work in this journal}

The International Journal of General Medicine is an international, peer-reviewed open-access journal that focuses on general and internal medicine, pathogenesis, epidemiology, diagnosis, monitoring and treatment protocols. The journal is characterized by the rapid reporting of reviews, original research and clinical studies across all disease areas.

\section{Dovepress}

The manuscript management system is completely online and includes a very quick and fair peer-review system, which is all easy to use. Visit http://www.dovepress.com/testimonials.php to read real quotes from published authors. 